\title{
Biomimetic Sulfide Oxidation by the Means of Immobilized Fe(III)-5,10,15,20-tetrakis(pentafluorophenyl)porphin under Mild Experimental Conditions
}

\author{
Paolo Zucca, ${ }^{1,2}$ Gianmarco Cocco, ${ }^{2}$ Manuela Pintus, \\ Antonio Rescigno, ${ }^{2}$ and Enrico Sanjust ${ }^{2}$ \\ ${ }^{1}$ Consorzio UNO Università Oristano, 09170 Oristano, Italy \\ ${ }^{2}$ Unità di Chimica Biologica e Biotecnologie Biochimiche, Dipartimento di Scienze Biomediche (DiSB), Università di Cagliari, \\ Complesso Universitario, 09042 Monserrato, Italy
}

Correspondence should be addressed to Enrico Sanjust; sanjust@unica.it

Received 27 May 2013; Revised 16 September 2013; Accepted 16 September 2013

Academic Editor: Theocharis C. Stamatatos

Copyright ( 2013 Paolo Zucca et al. This is an open access article distributed under the Creative Commons Attribution License, which permits unrestricted use, distribution, and reproduction in any medium, provided the original work is properly cited.

\begin{abstract}
This paper describes the oxidation of inorganic sulfide to sulfate, minimizing the formation of elemental sulfur. The described catalytic reaction uses dilute hydrogen peroxide at nearly neutral $\mathrm{pH}$ values in the presence of a bioinspired, heterogenized, and commercial ferriporphin. A substantial increase of the percentage of sulfide converted to sulfate is obtained in comparison with the yields obtained when working with hydrogen peroxide alone. The biomimetic catalyst also proved to be a much more efficient catalyst than horseradish peroxidase. Accordingly, it could be suitable for large-scale applications. Further studies are in progress to drive sulfate yields up to nearly quantitative.
\end{abstract}

\section{Introduction}

Recently, emissions containing hydrogen sulfide $\left(\mathrm{H}_{2} \mathrm{~S}\right)$ have been a health and environmental issue since it is unfortunately a very toxic compound for many human tissues [1], produced by many human activities.

Many chemical and physical methods have been proposed for its degradation [2-10]. However, they are usually featured by extreme operational conditions, turning the whole processes to be economically impacting.

Also, microbiological methods have been suggested, sho wing however several problems concerning the long time of reaction, stability, and compatibility of the rubbery membranes with the gas components $[11,12]$.

Even an enzymatic alternative has been described [1315], since organic sulfides (thioethers, R-S-R ${ }^{\prime}$ ) can be selectively oxidized to the corresponding sulfoxides and sulfones under very mild conditions with the help, for example, of BDS (biodesulfurization) $[14,15]$ catalyzed by enzymes such as oxygenases. However, the industrial applicability of enzymatic BDS has not yet been obtained, since the enzyme sources are limited and the costs are too high [13]. Not necessarily BDS leads to sulfur elimination from sulfur-containing organic molecules. In most cases, thiols and thioethers, respectively, change to sulfonic acid and sulfones. An alternative approach to eliminate thiols has been proposed, involving the combined action of mushroom tyrosinase, air, and suitable catechols. The $o$-quinones arising from the enzyme action covalently bind thiols leading to odorless compounds [16].

Recently, also metalloporphins have been suggested as catalysts for removal of thioethers [13, 17, 18]. These macrocycles represent a very versatile class of redox catalysts, being able to oxidize different recalcitrant organic compounds, under quite mild operational conditions [19-23].

However, in order to achieve an inexpensive and feasible process, the immobilization of the catalysts should be performed, in order to allow catalysts recovery, proper ligand supply, and stabilization of the catalysts [24, 25]. In our previous studies, we reported the immobilization of some metalloporphins onto solid supports emulating the structure of cytochrome P-450 and ligninolytic peroxidases. These 


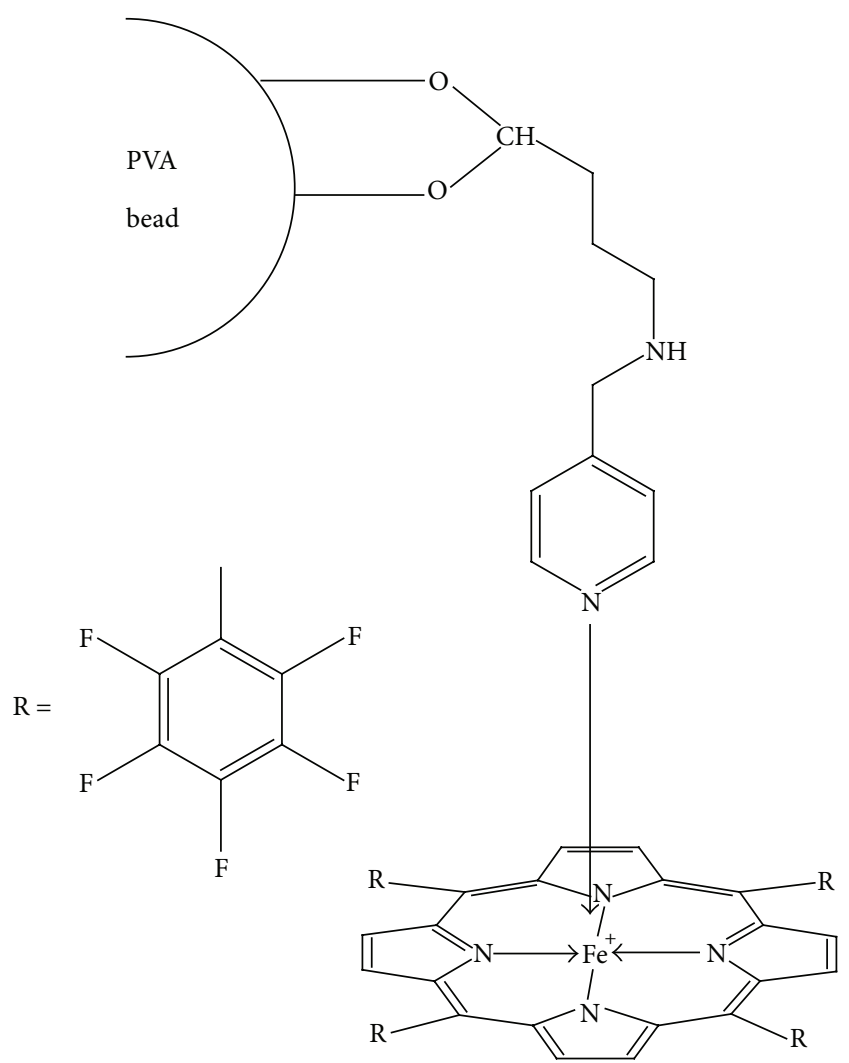

Figure 1: Proposed structure of the catalytic adduct PP-PVA/ FeTFPP.

catalytic adducts were able to oxidize both lignin model compounds (recently reviewed in [26]) and durable textile dyes [27-29].

In this paper, we describe the immobilization of a commercially available Fe-porphin onto a solid support grafted with pyridine residues (Figure 1 [30]). The ability of this adduct to oxidize sulfide ion leading to sulfate has been studied, focusing on the minimization of the amount of elemental sulfur produced. The catalytic conditions have been fully evaluated, in the perspective of a mild and feasible industrial process. Also, a comparison with an enzymatic system has been performed.

\section{Experimental}

All the reagents used were of the best grade available and were used as purchased without further purification. Fully hydrolysed PVA, Av. MW 30,000-50,000, was from Aldrich (Milan, Italy, cat. number 363138). Glutaraldehyde, as a 50\% aqueous solution, mainly containing oligomers in addition to the monomeric aldehyde, was from Fluka, Milan, Italy, cat. number 49629.

2.1. Preparation of FeTFPP/PP-PVA Adduct. The preparation FeTFPP/PP-PVA adduct was performed as already described [30].

Briefly, aminopropyl cross-linked PVA (AP-PVA) was prepared by treating $500 \mathrm{~mL}$ of a $10 \% \mathrm{w} / \mathrm{v}$ PVA aqueous solution with $5 \mathrm{~mL}$ 4-aminobutyraldehyde diethyl acetal, and $\mathrm{pH}$ was adjusted to $\sim 2$ with $6 \mathrm{M} \mathrm{HCl}$.

Then, $10 \mathrm{~mL}$ of a $50 \% \mathrm{v} / \mathrm{v}$ glutaraldehyde aqueous solution was added under stirring and the $\mathrm{pH}$ adjusted to $\sim 1$ with $6 \mathrm{M}$ $\mathrm{HCl}$. The obtained gel was kept at $90^{\circ} \mathrm{C}$ for $1 \mathrm{~h}$ and finally overnight at $25^{\circ} \mathrm{C}$. The product was ground for $10 \mathrm{~min}$ at 16,000 rpm with Ultra Turrax T25 Basic (IKA Technik, Milan, Italy), exhaustively washed with water, $0.1 \mathrm{M} \mathrm{NaOH}$, water again, 2-propanol, and finally carefully dried into a warm oven.

Each gram of the AP-PVA powder was suspended in excess water and treated with $0.1 \mathrm{~mL}$ of 4-pyridinecarboxaldehyde. The $\mathrm{pH}$ was adjusted to 5 with $0.1 \mathrm{M}$ acetic acid/ sodium acetate buffer, and $0.5 \mathrm{~g}$ sodium cyanoborohydride was added. After $24 \mathrm{~h}$, the support was exhaustively washed with $0.1 \mathrm{M}$ aqueous glycerol, water, $0.1 \mathrm{M} \mathrm{NaOH}$, water again, and 2-propanol. The wet PP-PVA was then carefully dried overnight in a vacuum oven at $50^{\circ} \mathrm{C}$.

Each gram of PP-PVA was treated with $20 \mathrm{mg}$ FeTFPP, solubilized in $10 \mathrm{~mL}$ DMSO. The slurry was kept $24 \mathrm{~h}$ stirring in the dark (because of metalloporphin photosensitivity) and washed exhaustively at first with DMSO then with 2propanol. The adduct was finally dried at $50^{\circ} \mathrm{C}$ in a vacuum oven.

Bound metalloporphin was quantified by difference through spectrophotometric measurement (UltroSpec 2100 pro, Amersham Bioscience, Milan, Italy) at $411 \mathrm{~nm}\left(\varepsilon_{411}=\right.$ $115,000 \mathrm{M}^{-1} \mathrm{~cm}^{-1}$ in DMSO), as already described [30].

2.2. Catalytic Assay. A mixture containing $10 \mathrm{mg}$ of catalyst (corresponding to $0.67 \mathrm{mg} / 0.63 \mu \mathrm{mol}$ of ferriporphin) suspended in $1 \mathrm{~mL}$ of $25 \mathrm{mM}$ buffer solution containing $10 \mathrm{mM}$ $\mathrm{NaHS}$ and $45 \mathrm{mM}$ aqueous $\mathrm{H}_{2} \mathrm{O}_{2}$ was kept stirring at $25^{\circ} \mathrm{C}$ in the dark. Blank experiments were performed without one substrate or without catalyst. In a series of experiments, the concentrations of the substrates were varied within a proper range.

After prefixed periods of time, aliquots of the reaction solution $(500 \mu \mathrm{L})$ were treated with 100 E.U. of purified catalase for $30^{\prime}$ at $25^{\circ} \mathrm{C}$ and used for sulfide and sulfate quantification. In order to test catalytic performance at various $\mathrm{pHs}$, some McIlvaine buffers were used: $\mathrm{pH} 3, \mathrm{pH} 4$, pH 5, pH 6, pH 7, and pH 8 .

2.3. Sulfide and Sulfate Determination. Sulfide concentration was determined through photometric automatized cuvette test LCK653 (Hack Lange, Rheineck, Switzerland), using DR 2700 Portable Spectrophotometer (Hack Lange, Rheineck, Switzerland).

Sulfate was estimated after acidification of the samples $(200 \mu \mathrm{L})$ with $50 \mu \mathrm{L} 1 \mathrm{M} \mathrm{HCl}$. To remove some colloidal sulfur, when necessary, the acidified samples were centrifuged at $12,000 \times \mathrm{g}$ for $15 \mathrm{~min}$. Sulfate analysis was performed through photometric automatized cuvette test LCK153 (Hack Lange, Rheineck, Switzerland) based on a nephelometric measure.

2.4. Enzymatic Comparison. When horseradish peroxidase (HRP) was used, up to 1.5 E.U. was present in a final volume 
of $1 \mathrm{~mL}$ of $25 \mathrm{mM}$ buffer (pH 5), NaHS $10 \mathrm{mM}$, and $8.8 \mathrm{mM}$ $\mathrm{H}_{2} \mathrm{O}_{2}$.

\section{Results and Discussion}

In a previous paper, we had fully characterized the adduct PP-PVA/FeTFPP and studied its catalytic activity on ligninmodel compounds [30].

Under the described experimental conditions, PP-PVA/ FeTFPP was also able to achieve more than $70 \%$ conversion of the sulfide in $24 \mathrm{~h}$. In the same time, high amounts of sulfate were produced in the presence of hydrogen peroxide and the described heterogenized ferriporphin (more than $60 \%$ in $24 \mathrm{~h}$ ). Many combinations of different substrate concentrations (both peroxide and sulfide), catalyst, and buffers were tested to optimize the oxidation of sulfide to sulfate, with the aim of minimizing the production of elemental colloidal sulfur, whose removal is rather tedious.

An outstanding well-known property of hydrogen sulfide and of its anions $\mathrm{HS}^{-}$and $\mathrm{S}^{2-}$, in fact, is the high tendency to produce elemental sulfur upon mild oxidation. A milky colloidal turbidity arises in aqueous solutions, hindering a reliable analysis of residual sulfide unless such sulfur is not properly removed. Apart from the analytical concerns, from a technological perspective, the hardly recoverable colloidal sulfur is a drawback of any procedure involving hydrogen sulfide oxidation.

Elemental sulfur was not apparent during PP-PVA/ FeTFPP catalysis at neutral or alkaline $\mathrm{pH}$ values, where it was kept into the solution by residual sulfide, as polysulfides $\mathrm{S}_{x}{ }^{2-}$. These are readily decomposed upon acidification, and the arising sulfur was removed by centrifugation when appropriate, as noted above.

On the contrary, sulfate recovery would not be a problem, even at a plant scale, as it could be precipitated as calcium sulfate (gypsum), dried, and placed in landfill or eventually used as a soil improver in agriculture.

When the reaction was studied within a range of several hours, careful comparison with proper blank samples was necessary to take into account the slow autoxidation of sulfide, in particular at alkaline $\mathrm{pH}$ values.

The $\mathrm{pH}$ influence on the efficiency of sulfide removal was studied within the $\mathrm{pH}$ range 3-8. Figure 2 clearly shows that the optimal $\mathrm{pH}$ for sulfide oxidative removal is 5 , although a reasonable efficiency was still observed at $\mathrm{pH}$. The efficiency drop was higher on the acidic side of the studied range.

Taking into the due account the main aim of this study, namely, the complete oxidation of sulfide to sulfate, the correct stoichiometric ratio (1:4 at least) between sulfide and hydrogen peroxide must be maintained. Namely, the reaction is as follows:

$$
\mathrm{H}_{2} \mathrm{~S}+4 \mathrm{H}_{2} \mathrm{O}_{2} \longrightarrow \mathrm{SO}_{4}{ }^{2-}+4 \mathrm{H}_{2} \mathrm{O}+2 \mathrm{H}^{+}
$$

Otherwise, oxidation will be incomplete, and formation of colloidal sulfur and/or polysulfides becomes more likely. Furthermore, under such conditions, the analytical determination of reactants was quite uncertain.

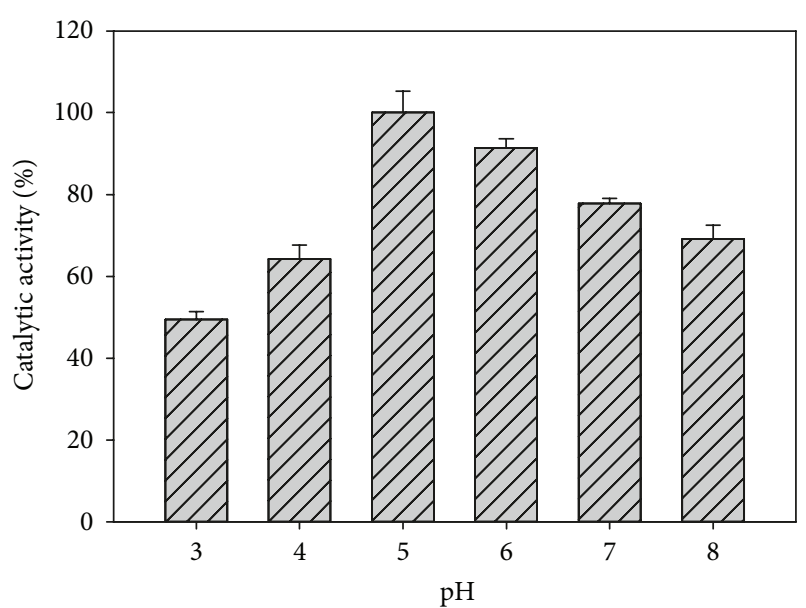

FIGURE 2: PP-PVA/FeTFPP oxidizes hydrogen sulfide with a $\mathrm{pH}$ dependent behavior. $10 \mathrm{mg}$ of catalyst reacted in the presence of $25 \mathrm{mM}$ buffer solution, $10 \mathrm{mM} \mathrm{NaHS}$, and $45 \mathrm{mM} \mathrm{H}_{2} \mathrm{O}_{2}(1 \mathrm{~mL}$ final volume) at $25^{\circ} \mathrm{C}$ for $24 \mathrm{~h}$. Results are expressed as sulfide conversion (i.e., sulfide removal regardless of the chemical nature of the oxidation product(s) $(n=5)$.

Such a problem of incomplete oxidation simply does not exist in the case of thiols (mercaptans) that are easily and cleanly oxidized to the corresponding sulfonic acids [31]. Organic sulfides (thioethers) are converted to the corresponding sulfones upon oxidation [32], also under metalloporphin catalysis [33-36]. Therefore, clean oxidation of hydrogen sulfide in water to sulfate under mild operative conditions is a serious challenge. However, the ability of concentrate hydrogen peroxide to oxidize hydrogen sulfide at slightly alkaline $\mathrm{pH}$ is well known by far. Anyway, we have faced the problem with the aid of a bioinspired catalyst, namely, an electron-deficient ferriporphin immobilized on to a suitable hydrophilic, insoluble support (Figure 1). This was found to be capable of promoting sulfide oxidation to sulfate under very low concentrations of hydrogen peroxide. As noted above, many data exist relative to metalloporphincatalyzed oxidation of sulfide to the corresponding sulfoxides and/or sulfones under proper experimental conditions. Somewhat surprisingly, no data have been found in the literature about hydrogen sulfide oxidation by metalloporphinbased catalysts, under experimental conditions similar to those effective in the case of organic sulfides. The already noted high tendency of $\mathrm{H}_{2} \mathrm{~S}$ to be oxidized with production of colloidal elemental sulfur, in particular under alkaline conditions, is most probably the explanation of such a lack of published studies. A vast number of experimental trials were in fact necessary to find the optimal conditions to convert hydrogen sulfide to sulfate, taking into the due account that an excessive peroxide concentration could oxidatively destroy the same catalyst. A slight $\mathrm{H}_{2} \mathrm{~S}$ oxidation was seen also in the blank experiments where the immobilized metalloporphin was present and hydrogen peroxide was omitted from the reaction mixture. This could be explained by means of a hypothetical redox reaction where the ferric porphin was slowly reduced by $\mathrm{H}_{2} \mathrm{~S}$ to its ferrous counterpart. This could 


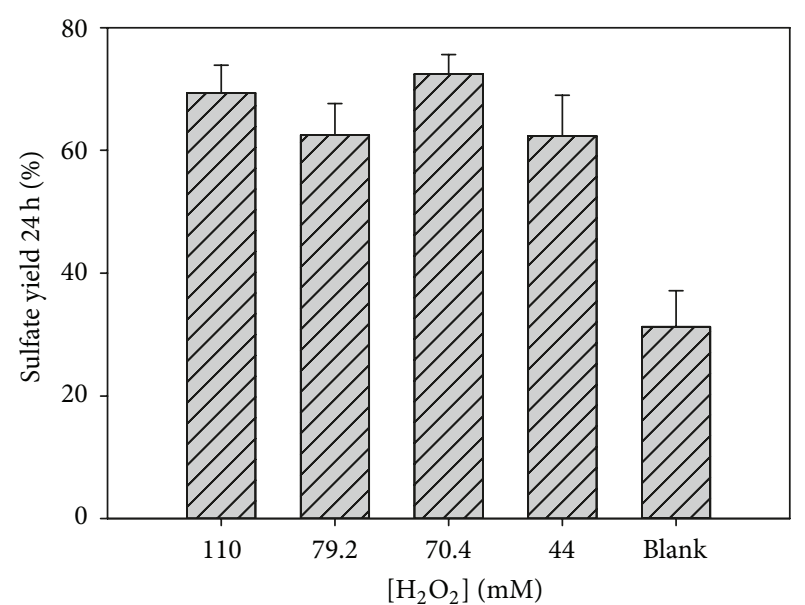

FIGURE 3: Sulfate yields obtained under PP-PVA-FeTFPP catalysis. Appropriate blank experiments were carried out in absence of hydrogen peroxide (Blank bar in the figure). $10 \mathrm{mg}$ of catalyst reacted in the presence of $25 \mathrm{mM}$ buffer solution $\mathrm{pH} 5,10 \mathrm{mM} \mathrm{NaHS}$, and the indicated $\mathrm{H}_{2} \mathrm{O}_{2}$ at $25^{\circ} \mathrm{C}$ for $24 \mathrm{~h}$ (final volume $\left.1 \mathrm{~mL}\right)(n=5$ ).

TABLE 1: Multicycle activity of the supported metalloporphine. $10 \mathrm{mg}$ of catalyst reacted in the presence of $25 \mathrm{mM}$ buffer solution, $10 \mathrm{mM}$ $\mathrm{NaHS}$, and $45 \mathrm{mM} \mathrm{H}_{2} \mathrm{O}_{2}$ (1 $\mathrm{mL}$ final volume) at $25^{\circ} \mathrm{C}$ for $2 \mathrm{~h}(n=3)$.

\begin{tabular}{lc}
\hline Cycle & \% Residual activity \\
\hline 1 & 100 \\
2 & 91 \\
3 & 90 \\
4 & 80 \\
5 & 78 \\
6 & 76 \\
7 & 71 \\
8 & 63 \\
\hline
\end{tabular}

in turn react with molecular oxygen thus regenerating the ferric catalyst and closing the catalytic cycle.

Also, hydrogen peroxide in the absence of the ferriporphin catalyst could oxidize hydrogen sulfide. However, the yields of sulfate are sharply lower, whereas more colloidal sulfur was formed. All the sulfate yields upon catalytic oxidation compared to the described blank experiments are summarized in Figure 3.

PP-PVA/FeTFPP was also able to keep its catalytic activity after several catalytic cycles. The results summarized in Table 1 showed that over $60 \%$ of initial catalytic activity is maintained after 8 catalytic cycles.

The biomimetic oxidation of PP-PVA/FeTFPP was also compared with enzymatic catalysis by the means of horseradish peroxidase (HRP). The results are summarized in Figure 4.

HRP was not able to exceed $30 \%$ sulfide conversion, even at the highest concentration tested. In the same condition, PP-PVA/FeTFPP allowed a twofold higher conversion, being

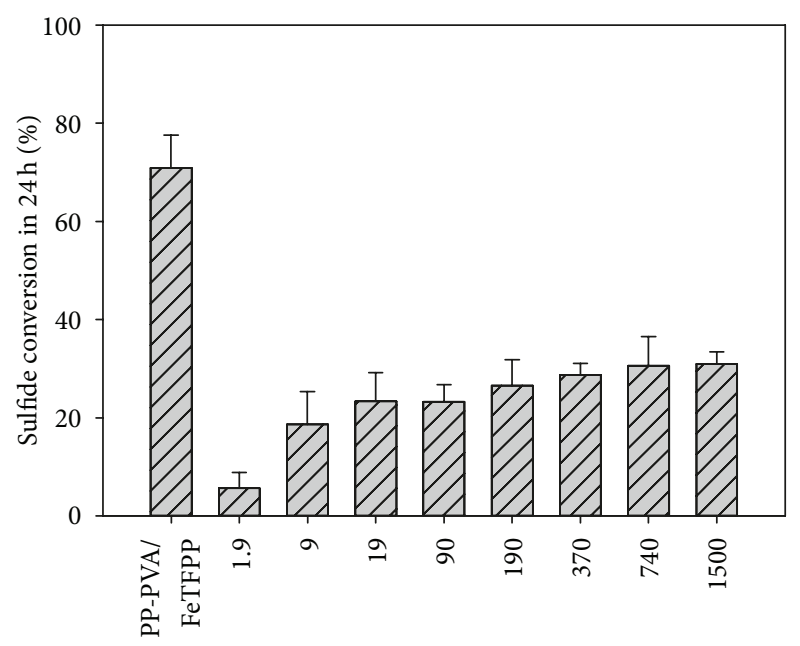

HRP (milli-E.U.)

FIgURE 4: Comparison between the biomimetic catalysis and horseradish peroxidase (HRP). The indicated E.U. of HRP was incubated in a final volume of $1 \mathrm{~mL}$ of $25 \mathrm{mM}$ buffer $\mathrm{pH} 5,10 \mathrm{mM}$ $\mathrm{NaHS}$, and $8.8 \mathrm{mM} \mathrm{H}_{2} \mathrm{O}_{2}$. PP-PVA/FeTFPP catalysis occurred in the same conditions described in Figure $3(n=5)$.

therefore quite a more promising large-scale alternative for sulfide treatment.

With respect to the possible oxidation mechanism(s), some different paths could be hypothesized (Figure 5). A possibility is the "classical" peroxidase-like mechanism already proposed for enzymatic sulfoxidation of thioethers [37]. In this path, the Compound I analogue $\mathrm{Porph}^{+\bullet} \mathrm{Fe}^{(\mathrm{IV})}=\mathrm{O}$ extracts one electron from $\mathrm{H}_{2} \mathrm{~S}$ or $\mathrm{HS}^{-}$leading to radical species $\mathrm{H}_{2} \mathrm{~S}^{+\bullet}$ or $\mathrm{HS}^{\circ}$, respectively. These could in turn react with the solvent water so triggering the further oxidation. Alternatively, the radical species arising from sulfide oxidation reacts with the Compound II analogue PorphFe ${ }^{(\mathrm{IV})}=\mathrm{O}$ (oxygen rebound mechanism). The intervention of the solvent should be most probably ruled out by analogy to that found in thioether sulfoxidation by hydrogen peroxide in the presence of the same ferriporphin described here [38]. Instead, the oxygen rebound mechanism should be the main path leading from sulfide to sulfate, under PP-PVA/FeTFPP catalysis. This hypothesis is strengthened by the observation that thioethers are oxidized to their sulfoxide counterparts by horseradish and lignin peroxidases, with incorporation of ${ }^{18} \mathrm{O}$ in the arising sulfoxides, when the oxygen donor is $\mathrm{H}_{2}{ }^{18} \mathrm{O}_{2}$. Anyway, the arising sulfoxides are formed with low yields, owing to the low tendency of peroxidase to transfer their oxygen from the corresponding Compound I to the substrate [39]. A remarkable exception is that of chloroperoxidases that follow a direct oxygen transfer mechanism [40]. Not surprisingly, the peroxidase we have chosen (horseradish peroxidase) for the reasons of the low costs related to a potential plant scale application was rather unsatisfactory also as a sulfide oxidation catalyst, even when used in high concentrations relative to those of the sulfide substrate. So, we have concluded 


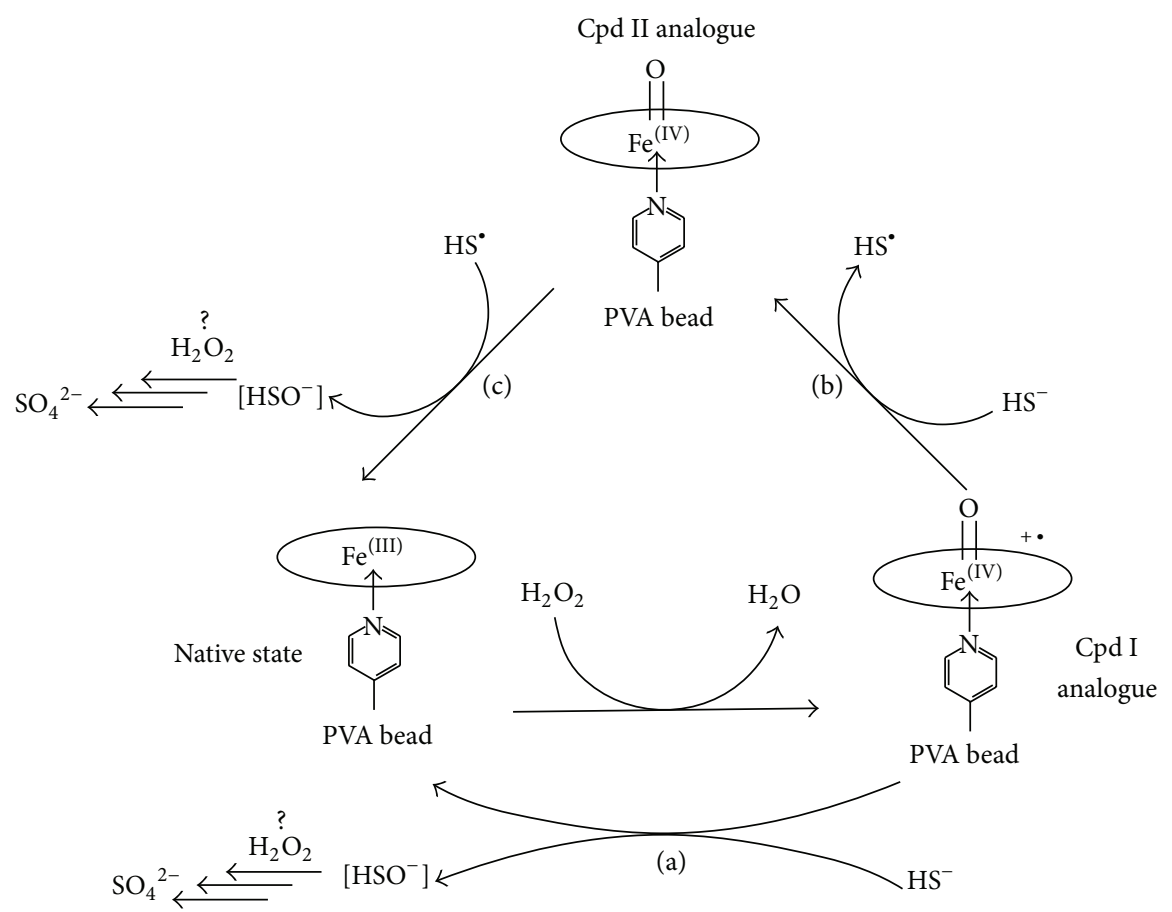

FiguRE 5: Proposed catalytic path for the immobilized metalloporphin. Path (a) represents the direct oxygen transfer from compound I analogue to sulfide. Paths (b) and (c) represent the rebound mechanism via compound II.

that hydrogen sulfide removal by hydrogen peroxide through peroxidase catalysis is not a feasible process.

In the case of metalloporphin catalysis a direct transfer of the oxygen atom from the Compound I analogue to the sulfur in sulfide could be envisaged and has been discussed in the literature with concerns to thioethers (path (a) of Figure 5 [39, 41]). However, the prevailing view is a rebound mechanism for these substrates [38] (paths (b) and (c) of Figure 5). In the case of (hydrogen) sulfide, an electron transfer from the (hydrogen) sulfide to the Compound I analogue would be immediately followed by an oxygen transfer from the arising Compound II analogue to the sulfide radical. By this way, we suggest that an extremely reactive and transient sulfenic intermediate $\mathrm{HSOH}$ or $\mathrm{HSO}^{-}$should arise, quickly evolving to more oxidized sulfur compounds and finally to sulfate, most probably by the direct action of excess hydrogen peroxide, possibly without any need of further metalloporphin catalysis. As a point of fact, the alternative hypothesis postulating a direct oxygen transfer should anyway lead to the same products.

\section{Conclusion}

We have shown the ability of a commercial metalloporphin, immobilized on to a cross-linked functionalized hydrophilic polymer to catalyze the hydrogen sulfide oxidation to sulfate, under very mild operative conditions and avoiding the formation of significant amount of elemental sulfur. Therefore, a diluted and nearly neutral hydrogen peroxide solution could be a tool to accomplish the oxidation in the presence of the described heterogenized ferriporphin. Biomimetic adduct also led to better catalytic performances than its enzymatic counterpart. PP-PVA/FeTFPP could be therefore a feasible alternative also in the large-scale process of $\mathrm{H}_{2} \mathrm{~S}$ removal.

\section{Abbreviations}

PVA: Poly(vinylalcohol)

AP-PVA: 3-Aminopropyl-functionalized PVA, cross-linked with glutaraldehyde

PP-PVA: 4'-Pyridylmethyl-3-aminopropylfunctionalized PVA, cross-linked with glutaraldehyde

FeTFPP: 5,10,15,20-Tetrakis(pentafluorophenyl) porphin-iron(III) chloride.

\section{Conflict of Interests}

The authors declare that they have no conflict of interests.

\section{Acknowledgments}

This research was partly funded by Fondazione Banco di Sardegna (Project Code 861/2012) and Regione Autonoma Sardegna (PO Sardegna FSE 2007-2013, L.R.7/2007, Bando Giovani Ricercatori, Project CRP1_27, and PO Sardegna FSE 2007-2013, L.R.7/2007, Ricerca di Base Bando 2008, Project CRP1_408).

\section{References}

[1] S. Chou, M. Fay, S. Keith, L. Ingerman, and L. Chappell, Toxicological Profile for Hydrogen Sulfide, U.S. Department of Health and Human Services, Atlanta, Ga, USA, 2006. 
[2] T. K. Ghosh and E. L. Tollefson, "Kinetic and reaction mechanism of hydrogen sulfide oxidation over activated carbon in the temperature range of $125-200^{\circ} \mathrm{C}$," Canadian Journal of Chemical Engineering, vol. 64, no. 6, pp. 969-976, 1986.

[3] M. Govindan, S. J. Chung, J. W. Jang, and I. S. Moon, "Removal of hydrogen sulfide through an electrochemically assisted scrubbing process using an active $\mathrm{Co}$ (III) catalyst at low temperatures," Chemical Engineering Journal, vol. 209, no. 1, pp. 601-606, 2012.

[4] J. R. Kastner and K. C. Das, "Wet scrubber analysis of volatile organic compound removal in the rendering industry," Journal of the Air and Waste Management Association, vol. 52, no. 4, pp. 459-469, 2002.

[5] E. Y. Lee, N. Y. Lee, K.-S. Cho, and H. W. Ryu, "Removal of hydrogen sulfide by sulfate-resistant Acidithiobacillus thiooxidans AZ11," Journal of Bioscience and Bioengineering, vol. 101, no. 4, pp. 309-314, 2006.

[6] P. Oyarzún, F. Arancibia, C. Canales, and G. E. Aroca, "Biofiltration of high concentration of hydrogen sulphide using Thiobacillus thioparus," Process Biochemistry, vol. 39, no. 2, pp. 165-170, 2003.

[7] A. Primavera, A. Trovarelli, P. Andreussi, and G. Dolcetti, "The effect of water in the low-temperature catalytic oxidation of hydrogen sulfide to sulfur over activated carbon," Applied Catalysis A, vol. 173, no. 2, pp. 185-192, 1998.

[8] M. Steijns and P. Mars, "The role of sulfur trapped in micropores in the catalytic partial oxidation of hydrogen sulfide with oxygen," Journal of Catalysis, vol. 35, no. 1, pp. 11-17, 1974.

[9] M. Fortuny, J. A. Baeza, X. Gamisans et al., "Biological sweetening of energy gases mimics in biotrickling filters," Chemosphere, vol. 71, no. 1, pp. 10-17, 2008.

[10] Y. Ma, J. Zhao, and B. Yang, "Removal of H2S in waste gases by an activated carbon bioreactor," International Biodeterioration and Biodegradation, vol. 57, no. 2, pp. 93-98, 2006.

[11] A. Makaruk, M. Miltner, and M. Harasek, "Biogas desulfurization and biogas upgrading using a hybrid membrane systemmodeling study," Water Science and Technology, vol. 67, no. 2, pp. 326-332, 2013.

[12] C. Liu, J. Liu, J. Li et al., "Removal of H2S by co-immobilized bacteria and fungi biocatalysts in a bio-trickling filter," Process Safety and Environmental Protection, vol. 91, no. 1-2, pp. 145-152, 2013.

[13] X. Zhou, X. Chen, Y. Wang, and Y. Jin, "Biomimetic oxidation of sulfides based on Fe III porphyrin under the mild conditions," in Proceedings of the International Conference on Biomedical Engineering and Biotechnology (ICBEB '12), pp. 101-103, 2012.

[14] T. Ohshiro, T. Hirata, and Y. Izumi, "Microbial desulfurization of dibenzothiophene in the presence of hydrocarbon," Applied Microbiology and Biotechnology, vol. 44, no. 1-2, pp. 249-252, 1995.

[15] C. Oldfield, O. Pogrebinsky, J. Simmonds, E. S. Olson, and C. F. Kulpa, "Elucidation of the metabolic pathway for dibenzothiophene desulphurization by Rhodococcus sp. strain IGTS8 (ATCC 53968)," Microbiology, vol. 143, no. 9, pp. 2961-2973, 1997.

[16] O. Negishi and T. Ozawa, "Effect of polyphenol oxidase on deodorization," Bioscience, Biotechnology and Biochemistry, vol. 61, no. 12, pp. 2080-2084, 1997.

[17] S. Zakavi, A. Abasi, A. R. Pourali, and S. Talebzadeh, "Metalloporphyrin-catalyzed chemoselective oxidation of sulfides with polyvinylpyrrolidone-supported hydrogen peroxide: a simple catalytic system for selective oxidation of sulfides to sulfoxides," Bulletin of the Korean Chemical Society, vol. 33, no. 1, pp. 35-38, 2012.

[18] X. Zhou, X. Chen, Y. Jin, and I. E. Markó, "Evidence of two key intermediates contributing to the selectivity of P450-biomimetic oxidation of sulfides to sulfoxides and sulfones," Chemistry, vol. 7, no. 10, pp. 2253-2257, 2012.

[19] G. Díaz-Díaz, M. C. Blanco-López, M. J. Lobo-Castañón, A. J. Miranda-Ordieres, and P. Tuñón-Blanco, "Hemo-acrylic polymers as catalyst for the oxidative dehalogenation of 2, 4, 6trichlorophenol. Chloroperoxidase's mimic imprinting effects," Journal of Molecular Catalysis A, vol. 353, no. 1, pp. 117-121, 2012.

[20] B. Fontaine, A. Nuzzo, R. Spaccini, and A. Piccolo, "Degradation of 2, 4-dichlorophenol and coupling into humic matter by oxidative biomimetic catalysis with iron-porphyrin," Journal of Geochemical Exploration, vol. 129, no. 1, pp. 28-33, 2012.

[21] A. Nuzzo and A. Piccolo, "Enhanced catechol oxidation by heterogeneous biomimetic catalysts immobilized on clay minerals," Journal of Molecular Catalysis A, vol. 371, no. 1, pp. 8-14, 2013.

[22] Q. Zhu, Y. Mizutani, S. Maeno, and M. Fukushima, "Oxidative debromination and degradation of tetrabromo-bisphenol A by a functionalized Silica-supported Iron (III)-tetrakis (p-sulfonatophenyl) porphyrin catalyst," Molecules, vol. 18, no. 5, pp. 5360-5372, 2013.

[23] P. Zucca, A. Rescigno, and E. Sanjust, "Ligninolytic peroxidaselike activity of a synthetic metalloporphine immobilized onto mercapto-grafted crosslinked PVA inspired by the active site of cytochrome P450," Chinese Journal of Catalysis, vol. 32, no. 11, pp. 1663-1666, 2011.

[24] A. M. D. Rocha Gonsalves and M. M. Pereira, "State of the art in the development of biomimetic oxidation catalysts," Journal of Molecular Catalysis A, vol. 113, no. 1-2, pp. 209-221, 1996.

[25] P. Zucca, G. Mocci, A. Rescigno, and E. Sanjust, "5,10,15,20Tetrakis(4-sulfonato-phenyl)porphine-Mn(III) immobilized on imidazole-activated silica as a novel lignin-peroxidase-like biomimetic catalyst," Journal of Molecular Catalysis A, vol. 278, no. 1-2, pp. 220-227, 2007.

[26] P. Zucca, A. Rescigno, A. C. Rinaldi, and E. Sanjust, "Biomimetic metalloporphines and metalloporphyrins as potential tools for delignification: molecular mechanisms and application perspectives," Journal of Molecular Catalysis A, 2013.

[27] P. Zucca, A. Rescigno, M. Pintus, A. C. Rinaldi, and E. Sanjust, "Degradation of textile dyes using immobilized lignin peroxidase-like metalloporphines under mild experimental conditions," Chemistry Central Journal, vol. 6, article 161, 2012.

[28] P. Zucca, C. Vinci, A. Rescigno, E. Dumitriu, and E. Sanjust, "Is the bleaching of phenosafranine by hydrogen peroxide oxidation catalyzed by silica-supported 5,10,15,20-tetrakis(sulfonatophenyl)porphine-Mn(III) really biomimetic?" Journal of Molecular Catalysis A, vol. 321, no. 1-2, pp. 27-33, 2010.

[29] P. Zucca, C. Vinci, F. Sollai, A. Rescigno, and E. Sanjust, "Degradation of Alizarin Red S under mild experimental conditions by immobilized 5,10,15,20-tetrakis(4-sulfonatophenyl) porphine- $\mathrm{Mn}(\mathrm{III})$ as a biomimetic peroxidase-like catalyst," Journal of Molecular Catalysis A, vol. 288, no. 1-2, pp. 97-102, 2008.

[30] P. Zucca, F. Sollai, A. Garau, A. Rescigno, and E. Sanjust, "Fe(III)-5,10,15,20-tetrakis(pentafluorophenyl)porphine supported on pyridyl-functionalized, crosslinked poly(vinyl alcohol) as a biomimetic versatile-peroxidase-like catalyst," Journal of Molecular Catalysis A, vol. 306, no. 1-2, pp. 89-96, 2009. 
[31] E. Cano-Serrano, J. M. Campos-Martin, and J. L. G. Fierro, "Sulfonic acid-functionalized silica through quantitative oxidation of thiol groups," Chemical Communications, vol. 9, no. 2, pp. 246-247, 2003.

[32] M. Kirihara, A. Itou, T. Noguchi, and J. Yamamoto, “Tantalum carbide or niobium carbide catalyzed oxidation of sulfides with hydrogen peroxide: Highly efficient and chemoselective syntheses of sulfoxides and sulfones," Synlett, no. 10, pp. 1557$1561,2010$.

[33] E. Baciocchi, M. F. Gerini, and A. Lapi, "Synthesis of sulfoxides by the hydrogen peroxide induced oxidation of sulfides catalyzed by iron tetrakis(pentafluorophenyl)porphyrin: scope and chemoselectivity," Journal of Organic Chemistry, vol. 69, no. 10, pp. 3586-3589, 2004.

[34] M. Moghadam, S. Tangestaninejad, V. Mirkhani, I. Mohammadpoor-Baltork, and A. A. Abbasi-Larki, "Biomimetic oxidation of sulfides with sodium periodate catalyzed by polystyrenebound manganese (III) tetrapyridylporphyrin," Applied Catalysis A, vol. 349, no. 1-2, pp. 177-181, 2008.

[35] A. Ghaemi, S. Rayati, S. Zakavi, and N. Safari, "Highly efficient oxidation of sulfides to sulfones with tetra-n-butylammonium hydrogen monopersulfate catalyzed by $\beta$-tri- and tetra-brominated meso-tetraphenylporphyrinatomanganese(III) acetate," Applied Catalysis A, vol. 353, no. 2, pp. 154-159, 2009.

[36] A. Rezaeifard, M. Jafarpour, H. Raissi, E. Ghiamati, and A. Tootoonchi, "Factors affecting the reactivity and selectivity in the oxidation of sulfides with tetra-n-butylammonium peroxomonosulfate catalyzed by $\mathrm{Mn}$ (III) porphyrins: significant nitrogen donor effects," Polyhedron, vol. 30, no. 4, pp. 592-598, 2011.

[37] H. B. Dunford, Heme Peroxidase, John Wiley \& Sons, New York, NY, USA, 1999.

[38] E. Baciocchi, M. F. Gerini, O. Lanzalunga, A. Lapi, and M. G. Lo Piparo, "Mechanism of the oxidation of aromatic sulfides catalysed by a water soluble iron porphyrin," Organic and Biomolecular Chemistry, vol. 1, no. 2, pp. 422-426, 2003.

[39] Y. Goto, T. Matsui, S.-I. Ozaki, Y. Watanabe, and S. Fukuzumi, "Mechanisms of sulfoxidation catalyzed by high-valent intermediates of heme enzymes: electron-transfer vs oxygen-transfer mechanism," Journal of the American Chemical Society, vol. 121, no. 41, pp. 9497-9502, 1999.

[40] E. Baciocchi, O. Lanzalunga, S. Malandrucco, M. Ioele, and S. Steenken, "Oxidation of sulfides by peroxidases. Involvement of radical cations and the rate of the oxygen rebound step," Journal of the American Chemical Society, vol. 118, no. 37, pp. 8973-8974, 1996.

[41] W. Ando, R. Tajima, and T. Takata, "Oxidation of sulfide with ArIO catalyzed with TPPM(III)Cl," Tetrahedron Letters, vol. 23, no. 16, pp. 1685-1688, 1982. 

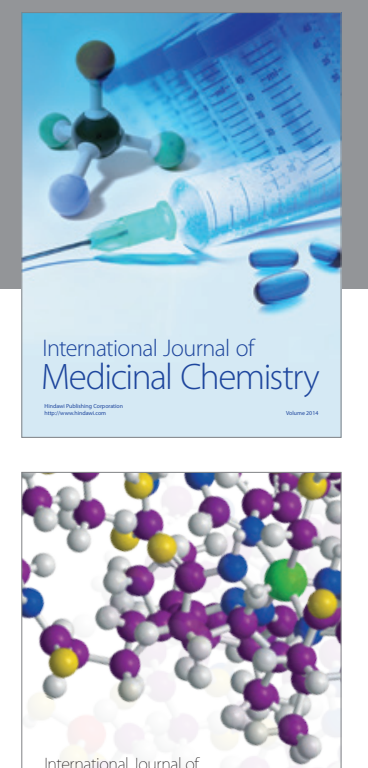

\section{Carbohydrate} Chemistry

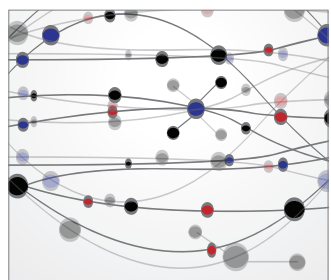

The Scientific World Journal
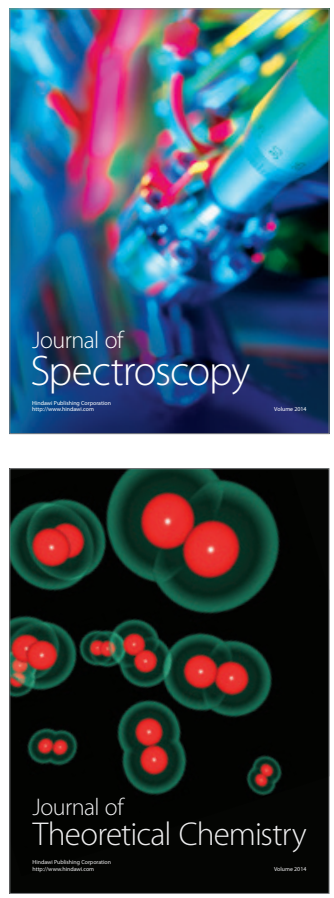
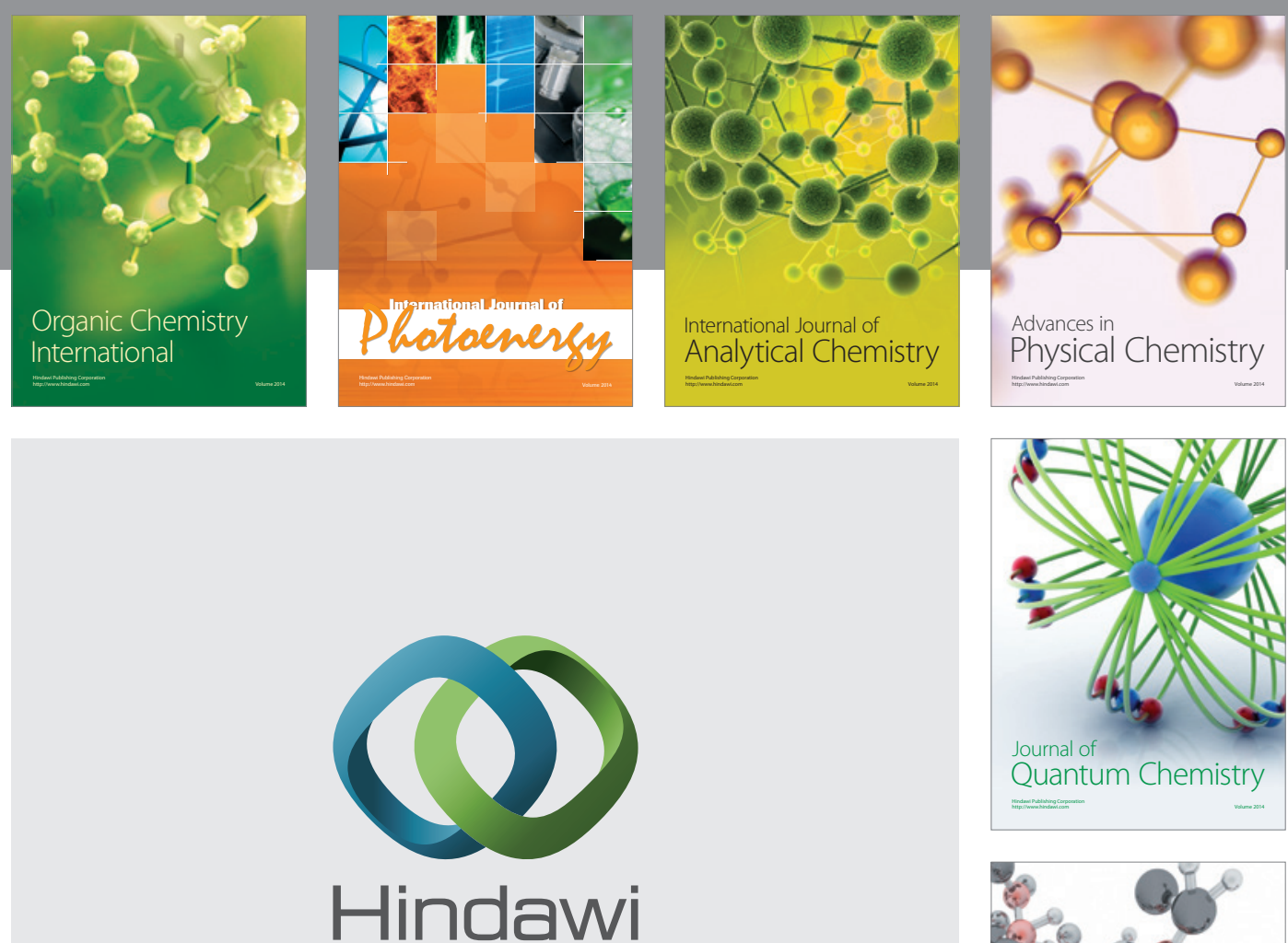

Submit your manuscripts at

http://www.hindawi.com

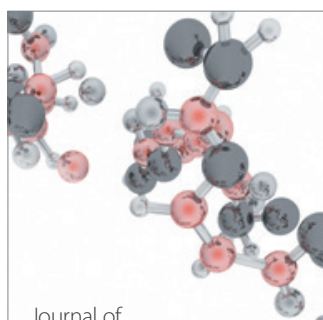

Analytical Methods

in Chemistry

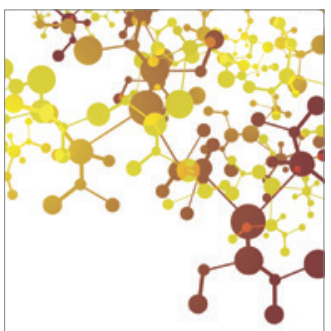

Journal of

Applied Chemistry

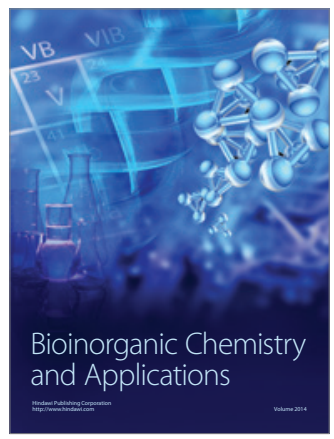

Inorganic Chemistry
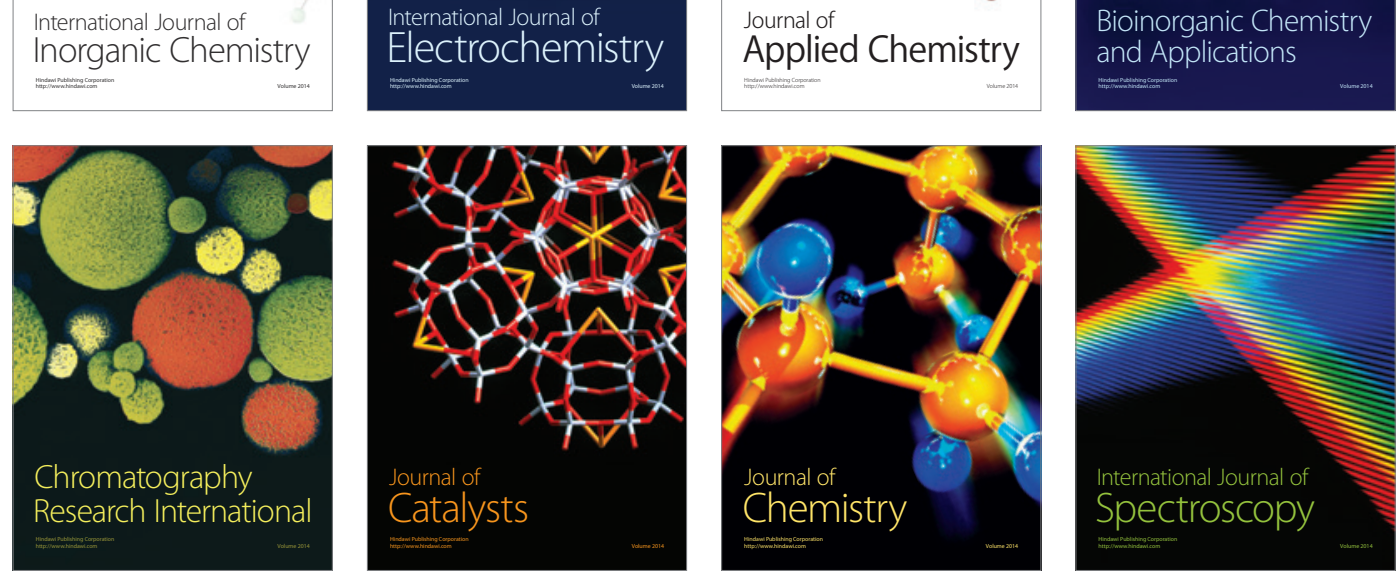